\title{
آلية التمكين الإداري في الفكر التنظيمي الحديث
}

الأستاذ الدكتور : عبد العالي دبلة، جامعة بسكرة، الجزائر

البـاحثة: وفـاء العمري، جامعة بسكرة، الجزائر

الملخص:

إن عصر العولمة و تسارع المعرفة و ازدهارها تستوجب تبني مفاهيم متطورة الأبها

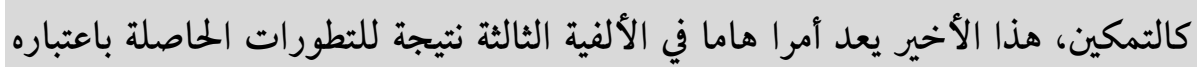

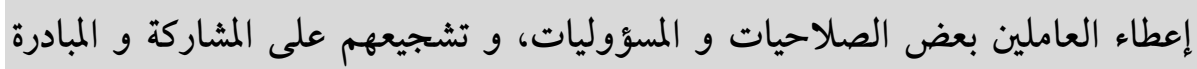

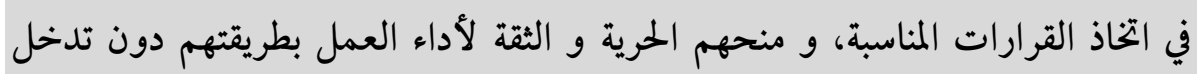

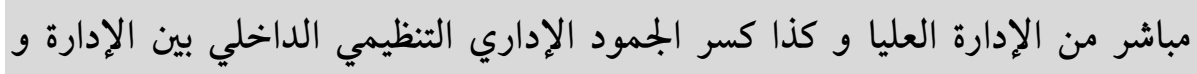

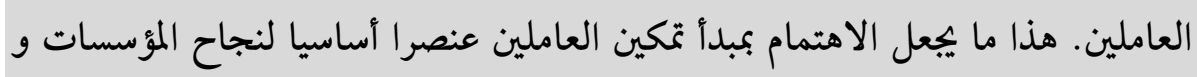

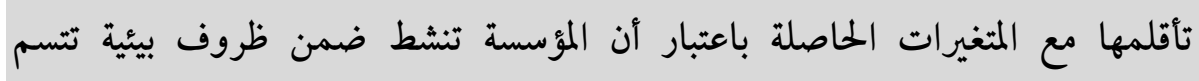

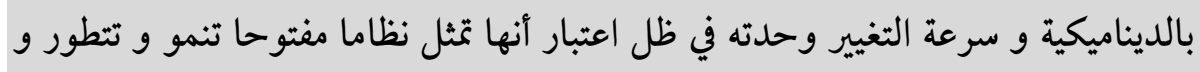

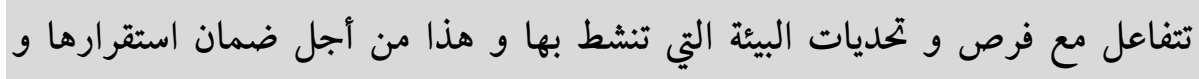
المحافظة على المركز التنافسي و تطويره .

\section{Abstract :}

The era of accelerated globalization and knowledge and their development requires the adoption of concept and an important feature in the third millennium allow the massive participation of workers and appropriate decision making initiative and give them confidence for freedom and without external interference, their work is out of the impasse internal administrative management between the administration and staff. That's what the attention on the principle allow workers an essential element of successful institutions and changes as an institution operating in ecological conditions and pace of change and unity in the conditions they are an open system to grow and grow and work with the environmental challenges and opportunities actively, and to ensure stability and preserve the status competitiveness and develop further. 
مقدَمـة:

اتجهت العلوم الاجتماعية و الإنسانية و خاصة الإدارة و العمل إلى

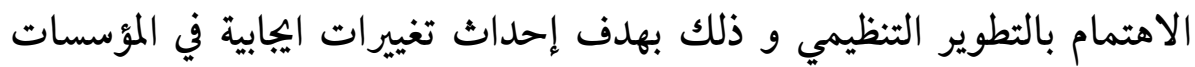
لمو اكبة التغييرات المتسارعة و يجعلها أكثر قدرة على حل المشكلاتلات و تقديم السلع

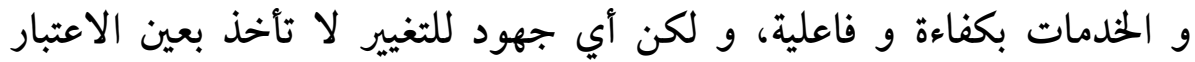

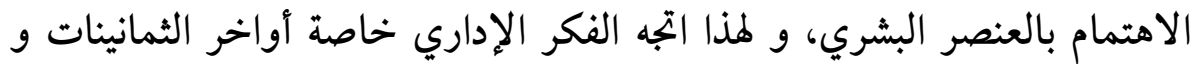

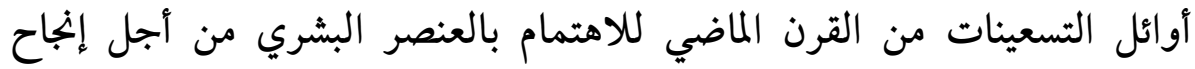

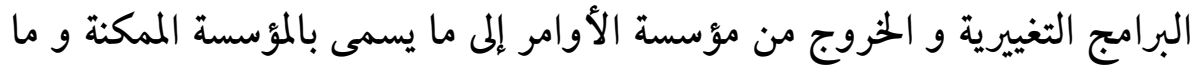

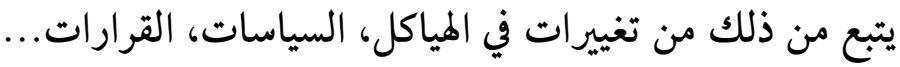

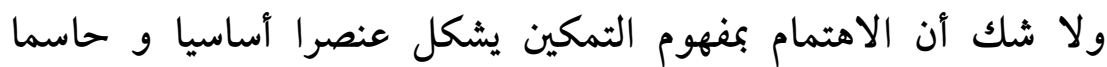
للمؤسسات خصوصا في الاتجاه نحو تبني و تطبيق المفاهيم الإدارية الحديثة.

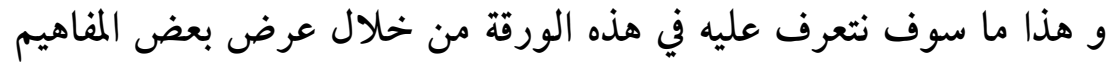

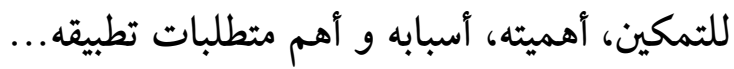
1- مفهوم التمكين le concept d'empowerment: لغة: عرف التمكين لغة على أنه: مصدرا افعل "مكن"، يقال "مكنه"الله من الشيء "تمكينا" و "أمكنه" منه، و استمكن الرجل

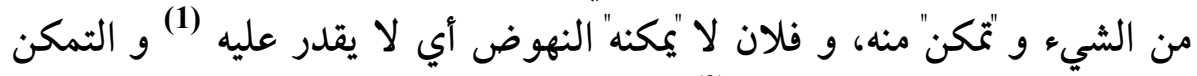

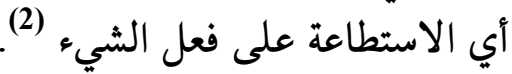
اصطلاحا: لاقى مصطلح التمكين في الآونة الأخيرة اهتمام العديد من الباحثين

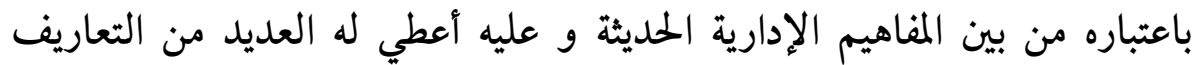
الاصطلاحية تصب بجملها في معنى شامل، من بينها نذكر مايلي: يعرف خضير الكبيسي التمكين بأنه "زيادة الاهتمام بالعاملين من خلال

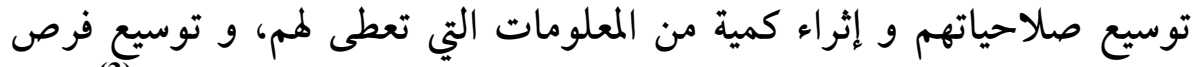

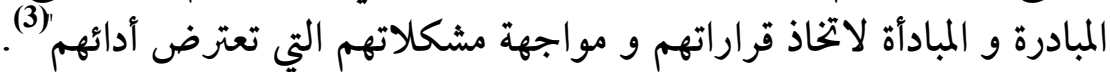


ركز هذا التعريف على الاهتمام بالعنصر البشري من خلال إمدادهم بكافة الصلاحيات.

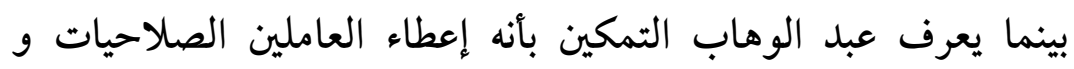

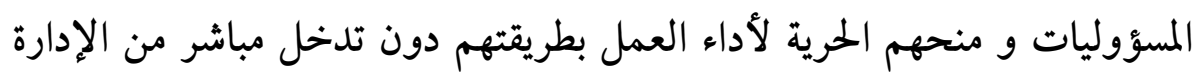

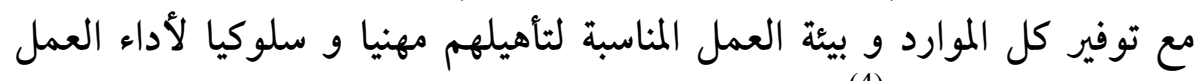

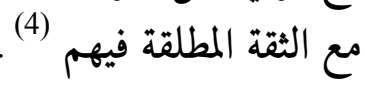

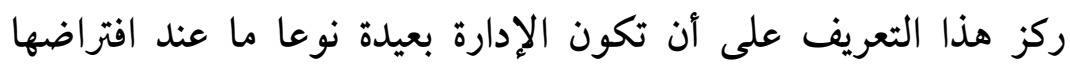

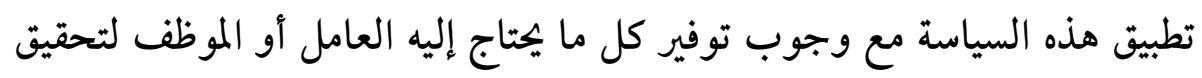

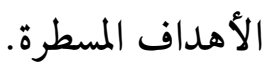

2.نشأة مصطلح التمكين: و هو كالآتي: (5)

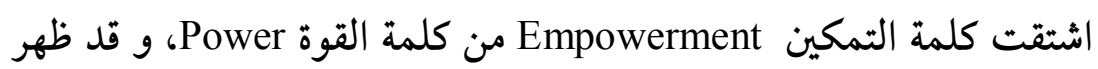

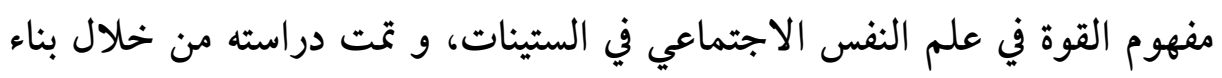

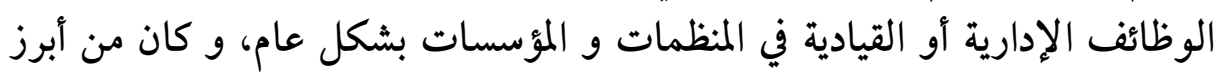

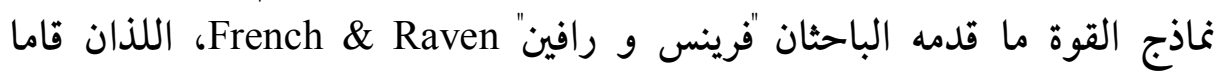

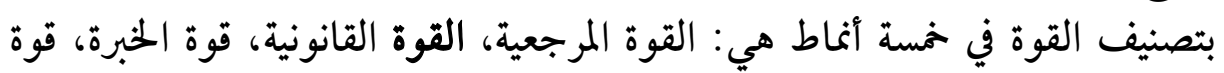

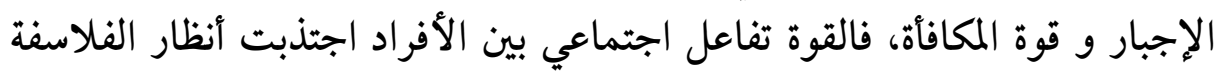

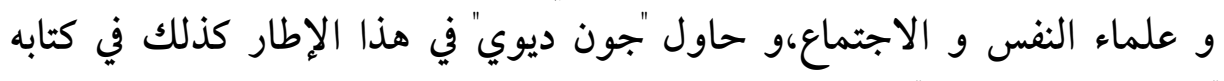

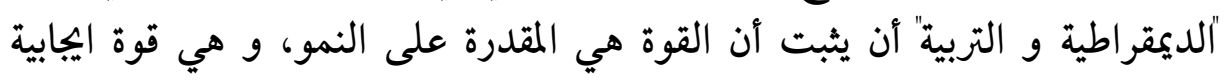

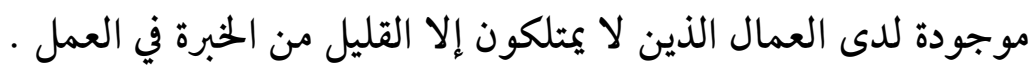

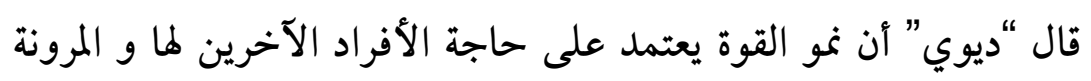

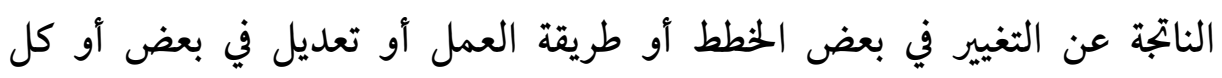

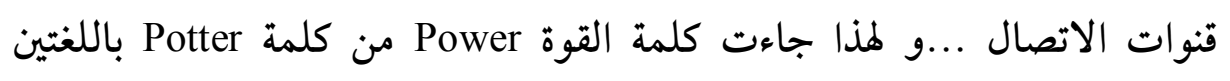

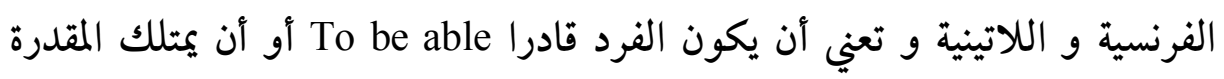

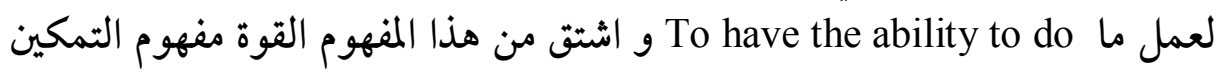
باعتباره عملية من الوعي و بناء الإمكانات التي تقود لمشاركة أكبر و القدرة على ملى ملى الفي 
صنع القرار و فعل التغيير، و هو يتضمن القدرة على الثفاوض و الثأثير في طبيعة

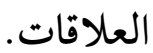

و بعد العديد من الدراسات التي قام بها الباحثين، انتشر مفهوم التمكين،

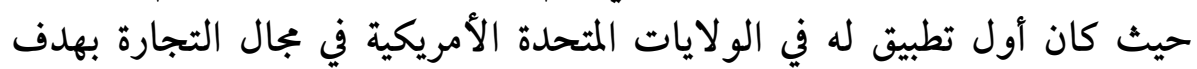

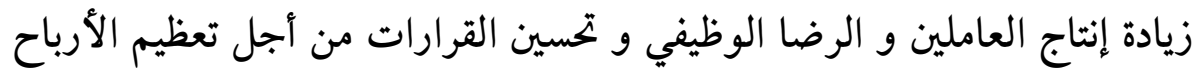
و هذا في إطار التغيير الحاصل في بعض الرضا العمليات و العيدين الإدارية.

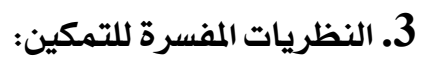

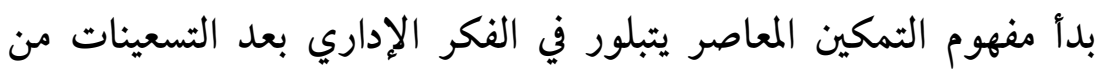

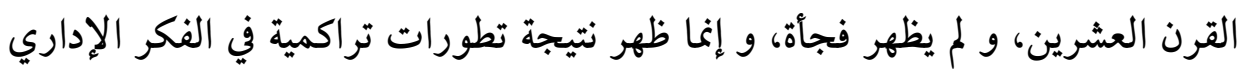

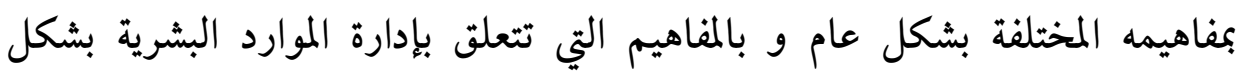

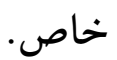

حيث بدأ التركيز عام 1920 على الجوانب الإنسانية في العمل (ليس بهدف

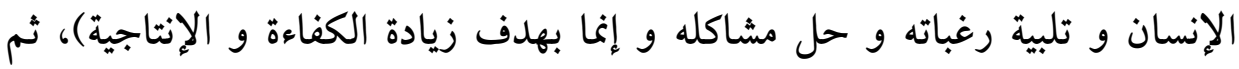

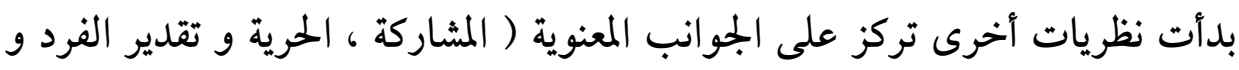
احترامه) . المنات

و من أهم تلك النظريات ما يلي:(6) 1.3 دراسات هوثورن و حركة العلاقات الإنسانية:

حيث بدأت بدراسة أثر العوامل المادية مثل ظروف العمل و مستوى الإضاءة

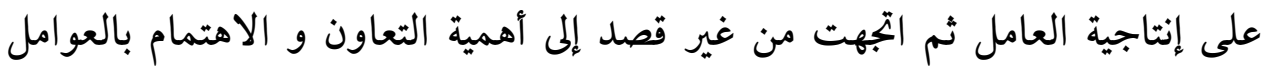

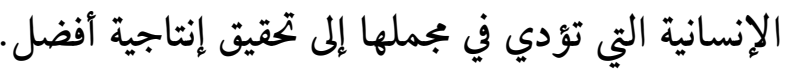

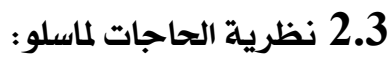

حيث اهتمت بدراسة قضايا خاصة أكثر تحديدا تتعلق بمشاركة العاملين في اتخاذ القرار و تحمل المسؤولية و تدوير العمل و تفويض الصلاحيات و توسيع العمل . 


\section{3 نظرية X و y لدوجلاس ماكريجور:}

حيث افترضت أن المديرون نوعان X و y حيث X ت Xثل المدير الذي يفترض

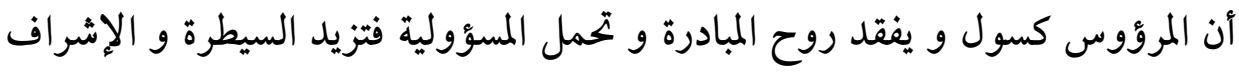

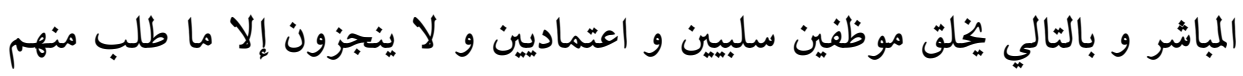
فقط.

أما y تمثل المدير الذي يفترض أن المرؤوس لديه قدرات خلاقة و حب

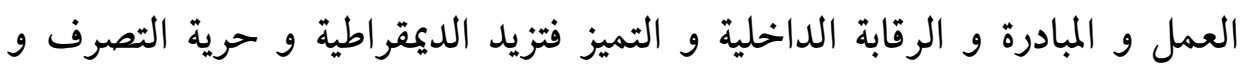

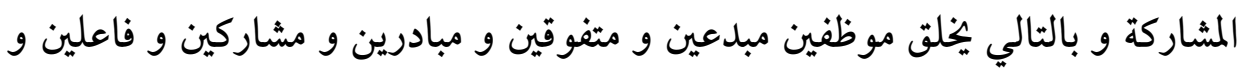
لديهم الشعور بالقيمة الحقيقية لقدراتهم. 4.3 الشخصية البالغة لدى كريس آرجريس:

حيث ينظر للإنسان على أنه بالغ و ناجح و عاقل و بالتالي فهو يمكنه أن

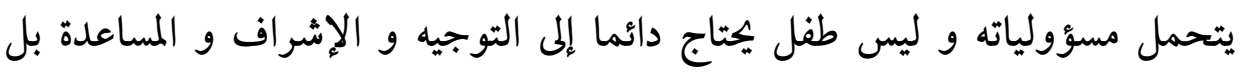
يجب توسيع نطاق صلاحياتهم و منحهم حق المشاركة و تحمل المسؤولية في العمل. 5.3

حيث يكون اهتمام العاملين بالأهداف العامة للمؤسسة ككل، مما يتطلب التعاون

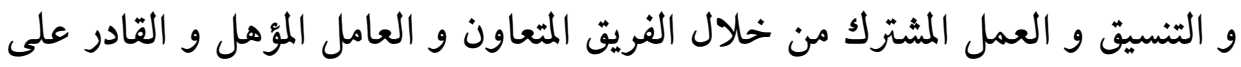
المساهمة الفاعلة. 6.3 التي تقوم على مبدأ التكيف مع المتغيرات الظرفية أو البيئية التي تواجه المنظمة و بالتالي فهي بجال مناسب و رحب للتفكير الخلاق و عدم التسرع. 7.3 الجودة الشاملة:

التي تعني بتحسين دائم و مستمر في مختلف نواحي المنظمة من خلال جودة أداء العامل و قدرته على المبادرة و تحمل المسؤولية. 
التي تعني أن يتقن العاملون الوظائف المختلفة قبل السعي للترقية إلى وظائف التف المانف

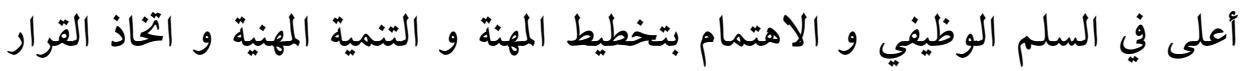
بشكل جماعي و التركيز على عمل الفريق.

9.3 منظمة التعليه:

التي تركز على العناصر الآتية: المعلومات و أهميتها في التعلم.

روح الفريق و أهميته في التعلم الجماعي الذي يضاعف التعلم الفردي. تحرير العامل من أي قيود تمنعه من التعلم و المشاركة. المشاركة التي هي جوهر عملية التعليم و التعلم. القيادة التي تحمل الرؤية نحو مؤسسة متعلمة و متطورة باستمرار. و مما سبق نرى أن مراحل تطور الفكر الإداري الحديث يتجه نحو تمكين العاملين و المبو توزيع الحق في المشاركة بين مختلف المستويات الإدارية.

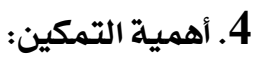
يمكن الحديث عن أهمية التمكين من عدة جوانب أهمها:

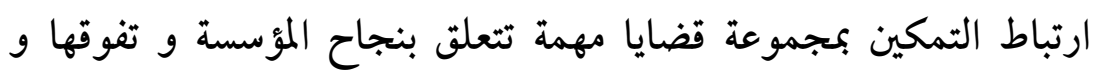

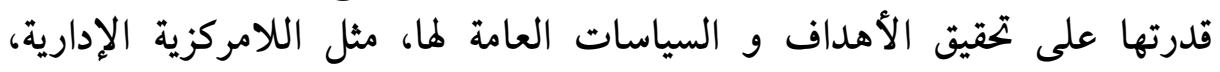

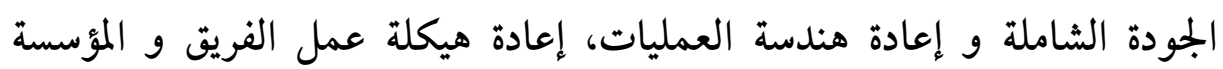
المتعلمة و المؤسسة الأفقية. (7) إعادة هندة المدة و لكي تحقق المؤسسة أهدافها، فعلى المديرين و الرؤساء إشراك العاملين في اتخاذ القرارات، فالمؤسسة تحتاج إلى معلوماتهم و خبراتهم و مهار اتهم و جهدهي المهدم

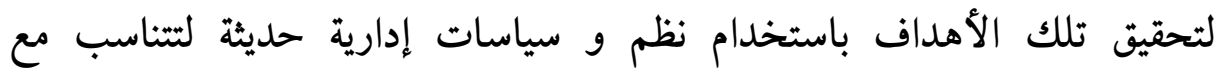


المتغيرات و التحديات العالمية المعاصرة، فالتمكين هو الأداة الأساسية لجعل المنظمة قادرة على مواجهة التحديات المستقبلية.

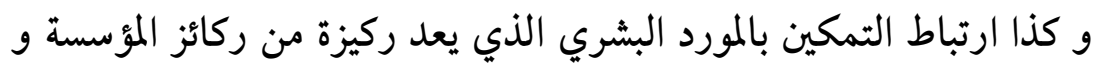

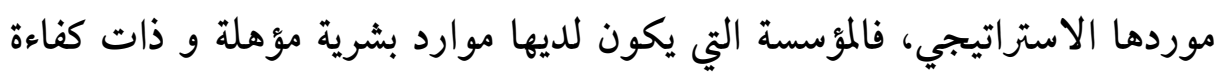

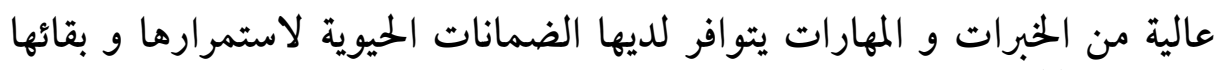
في الطليعة (8) لهذا سارعت المؤسسات للأخذ بالتمكين كفلسفة و أداة إدارية تساهم في

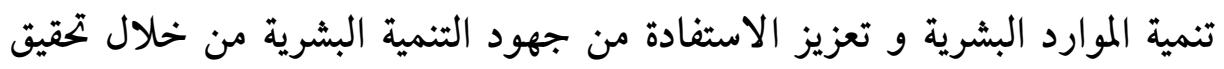

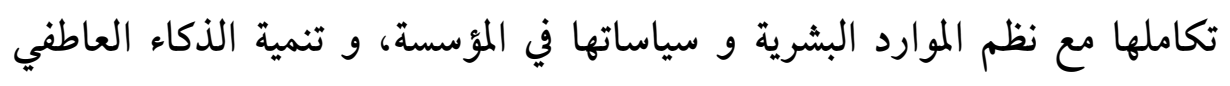

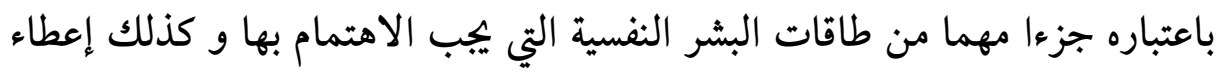

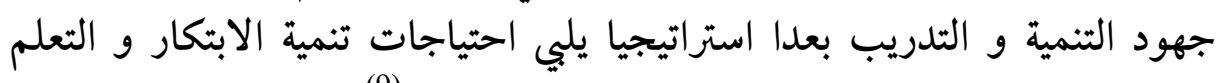

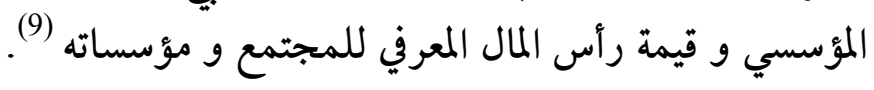

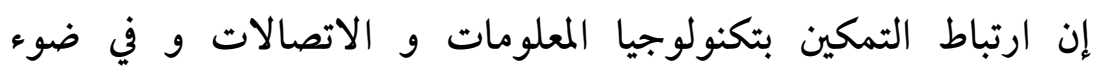

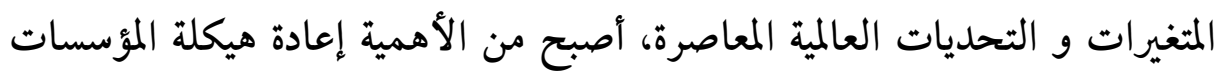

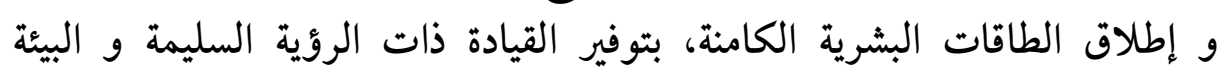

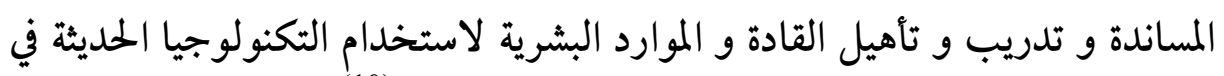
أداء المهام و الواجبات وفق أحداث المداد الوسائل و الأساليب (10)

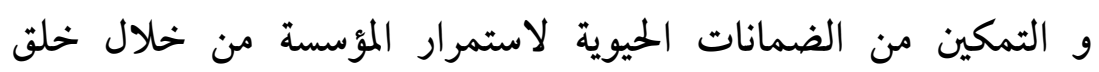

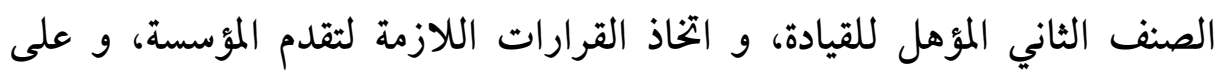

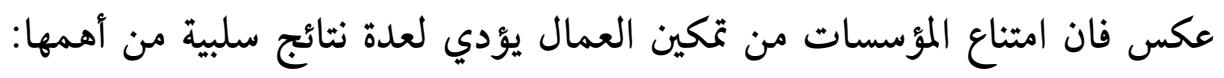

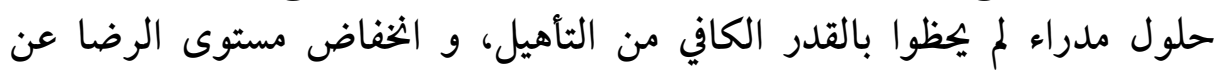

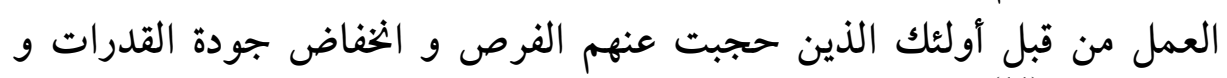

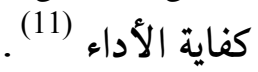




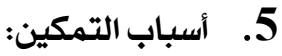

حدد أفندي مجموعة من الأسباب التي تدفع المنظمة إلى تبني مدخل التمكين ، في الآتي: (12) • حاجة المنظمة إلى أن تكون أكثر استجابة للسوق. تخفيض عدد المستويات الإدارية في الهياكل التنظيمية. تركيز اهتمام الإدارة العليا على القضايا الإستراتيجية. الاستغلال الأمثل للموارد المتاحة وخاصة البشرية للحفاظ على تطوير المنافسة. أهمية سرعة اتخاذ القرارات. إطلاق قدرات الأفراد الإبداعية والخلاقة. توفير المزيد من الرضا الوظيفي والتحفيز والانتماء التنظيمي. • خفض تكاليف التشغيل بتقليل عدد المستويات الإدارية غير الضرورية

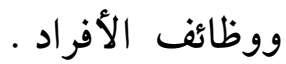

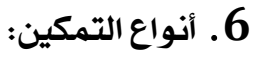

قسم Suominen عملية تمكين العاملين إلى ثلاثة أنواع (13): 1.6 التمكين الظاهري: ويشير إلى قدرة الفرد على إبداء رأيه وتوضيح وجهة نظره

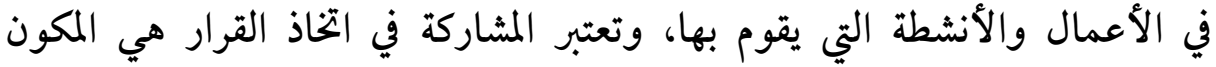
الجوهري لعملية التمكين الظاهري.

2.6 التمكين السلوكي: ويشير إلى قدرة الفرد على العمل في مجموعة من أجل حل

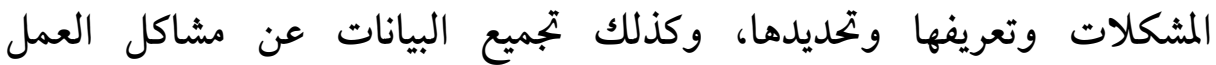
ومقترحات حلها، وبالتالي تعليم الفرد مهارات جديدة يمكن أن تستخدم في أداء 
3.6 تمكين العمل المتعلق بالنتائج: ويشمل قدرة الفرد على تحديد أسباب المشكلات

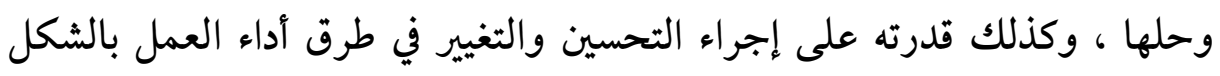
الذي يؤدي إلى زيادة فعالية المنظمة . والهرك 7.أبعاد التمكين:

يذكر (اندراوس و معايعة) أربعة أبعاد أساسية للتمكين حسب وجهة نظرهم وهي (14):

البعد الأول: المعنى (أو الإحساس بالجدوى)

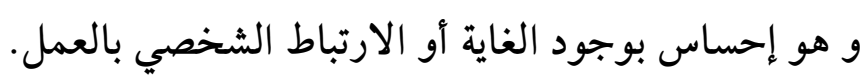
البعد الثاني: المقدرة و تشير إلى اعتقاد الفرد بقدرته على أداء فعاليات المهام بمهارة. البعد الثالث: حق الإرادة الشخصية و يعكس إحساس الفرد بالحرية إزاء طريقة أدائه لعمله. البعد الرابع: التاثير و يعني اعتقاد الفرد بأن له تأثيرا على القرارات التي يتم اتخاذها و السياسات التي التي التيات التئي

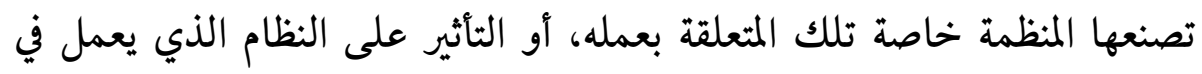
إطاره. 8. متطلبات التمكين:

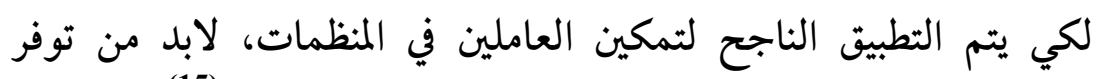

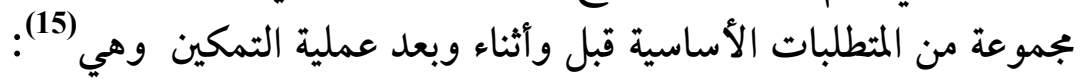
1.8 الثقة الإدارية:

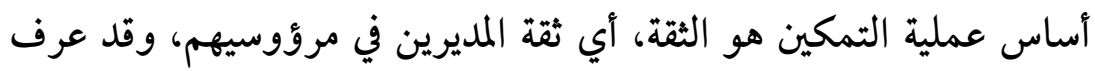

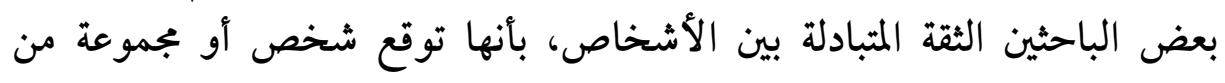


الأشخاص بأن معلومات أو تعهدات شخص آخر أو مجموعة من الأشخاص هي آلاصي

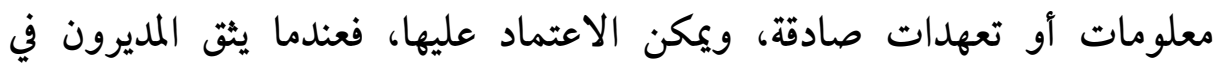

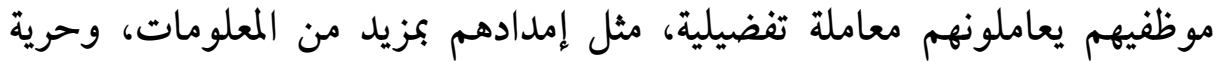

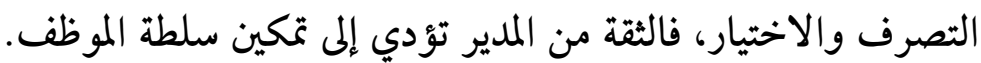

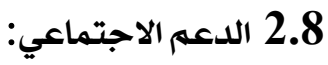

لكي يشعر الموظفون بالتمكين الفعلي، فلا بد وأن يشعروا بالدعم والتأييد

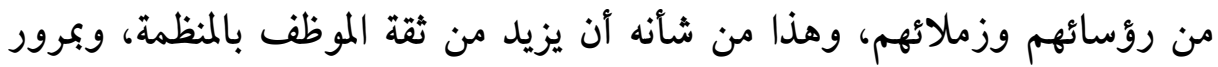

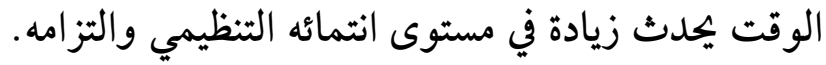

(الأهداف والرؤية المستقبلية :

يككن للمنظمة أن تحقق درجة عالية من التمكين، إذا أدرك العاملون بها

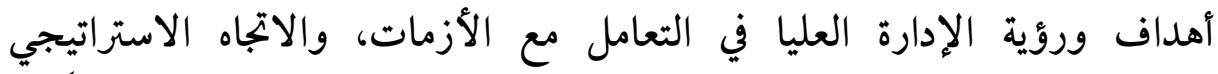

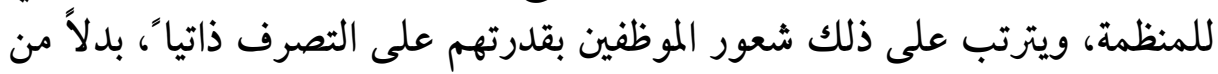

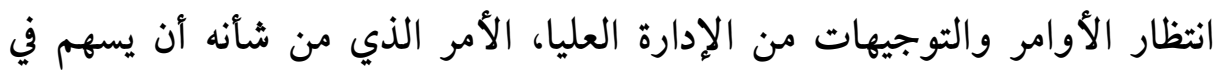

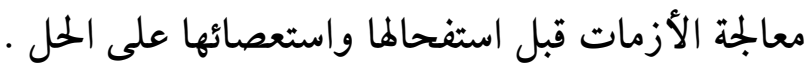

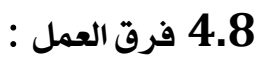

يتطلب تمكين العاملين ثقافة تنظيمية تؤكد على أهمية العنصر البشري،

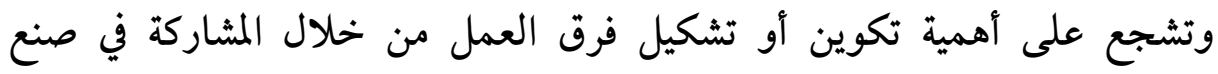

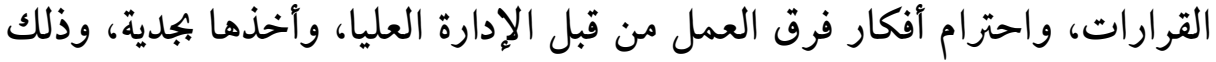

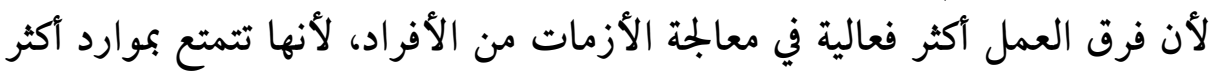

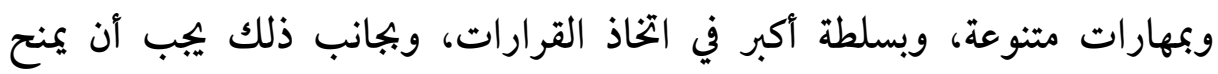

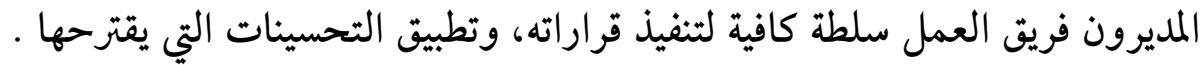




\section{: - n 5.8}

يعد الاتصال الفعال مع كل المستويات الإدارية، هو المفتاح الأساسي

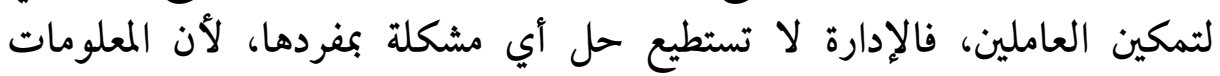

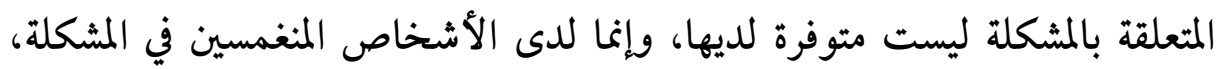

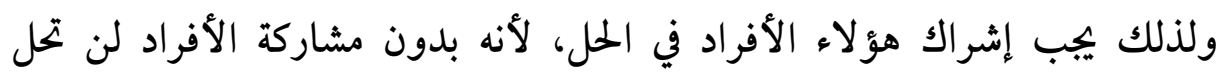

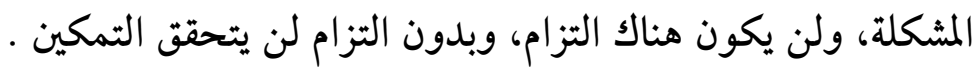

$$
6.8
$$

لا يمكن تمكين العاملين بدون توفير التدريب الملائم، لأنه لا يجب أن أن ألمان

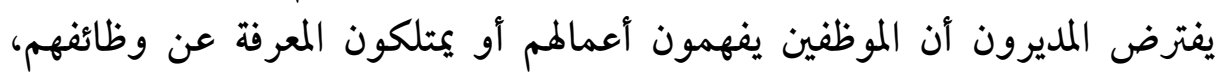

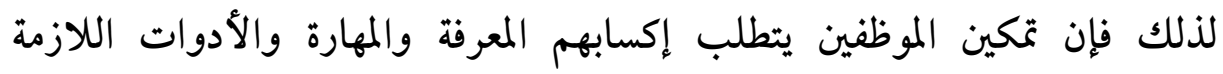
للتصرف الفعال بصفة مستمرة . لمكين الموطعن يتطل :

تعد المكافآت من أهم متطلبات تمكين العاملين، لأنها تعطي رسالة

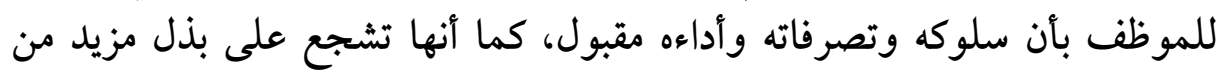
الجهد والتحسين المستمر للأعمال.

ويوضح الجدول رقم (1) : متطلبات تمكين العاملين وميزاته :

\begin{tabular}{|c|c|c|}
\hline الميزات & & متطلبات التمكين \\
\hline تحسين الأداء & & الثقة الإدارية \\
\hline إرضاء العملاء & & اللدعم الاجتماعي \\
\hline • حل المشكلات والأزمات & المهديل & • الأهداف \\
\hline
\end{tabular}




\begin{tabular}{|c|c|}
\hline & المستقبلية \\
\hline جودة الخلدمة & فرق العمل \\
\hline زيادة القدرة التنافسية & الاتصال الفعال \\
\hline ارتفاع الإنتاجية & التدريب المستمر \\
\hline تحقيق مكانة متميزة & مكافأة الموظفين \\
\hline
\end{tabular}

(16) (16)

9 . فوائد ومزايا التمكين :

يرى Umiker أن (التمكين) يفيد كلاءّمن المنظمة والفرد على النحو التالي:(17) 1.9 بالنسبة للمنظمة يحقق المزايا التالية :

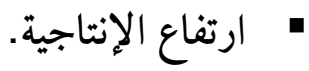
• انخفاض نسبة الغياب ودوران العمل ل • تحسين جودة الإنتاج أو الخدمات . • ت تحقيق مكانة متميزة . زيادة القدرة التنافسية.

زيادة التعاون على حل المشكلات. ارتفاع القدرات الابتكارية. 2.9 بالنسبة للفرد يحقق المزايا التالية : 1. إثباع حاجات الفرد من تقدير وإثبات الذات . 
2. ارتفاع مقاومة الفرد لضغوط العمل . 3. ارتفاع ولاء الفرد للمنظمة . 4. إحساس الفرد بالرضا عن وظيفته ورؤسائه . 5. ارتفاع الدافعية الذاتية للفرد . 6. ت تنمية الشعور بالمسؤولية . 7 7. ربط المصالح الفردية مع مصالح المنظمة . 10. معوقات تطبيق التمكين :

عند التطرق إلى تطبيق التمكين في المنظمات يكون من المفيد أن نفحص

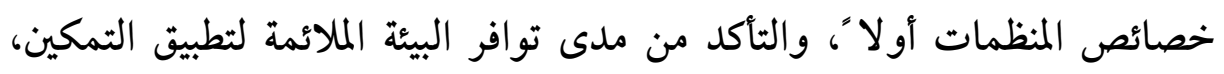

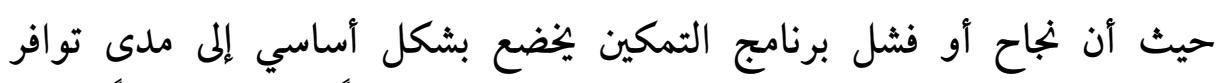

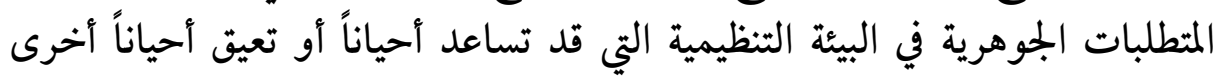

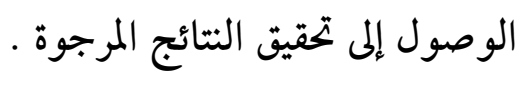
لذلك قد تواجه المنظمات بعض المعوقات التي قد تحد من قدرتها على تطبيق تمكين العاملين، ومن تلك المعوقات ما يلي (18) : 1 1. الميكل التنظيمي المرمي. 2. المركزية الشديدة في سلطة اتخاذ القرارات. 3. خوف الإدارة العليا من فقدان السلطة. 4. عدم الرغبة في التغيير. 5. خوف الإدارة الوسطى من فقدان وظائفها والسلطة. 6. خوف العاملين من تحمل السلطة والمسؤولية. 7. الأنظمة والإجراءات الصارمة التي لا تشجع على المبادآة والابتكار. 
8. السرية في تبادل المعلومات .

9. و ضعف نظام التحفيز .

10. تفضيل أسلوب القيادة الإدارية التقليدية .

11. ضعف التدريب والثطوير الذاتي . 10.

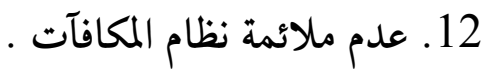

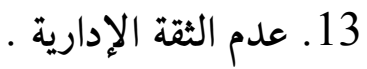

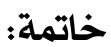

إن نجاح برامج التمكين يتطلب بالدرجة الأولى اقتناع المؤسسة و الإدارة

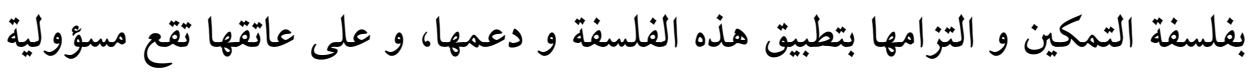

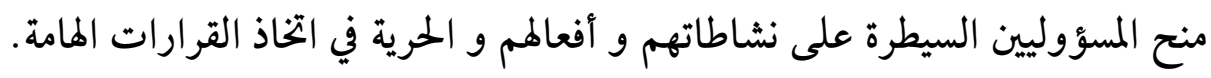

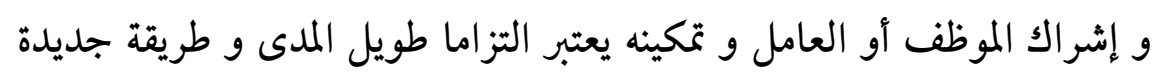

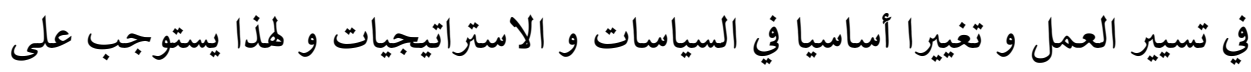
الإدارة إعطاء الوقت الكافي لتحقيق المدف المرجو من هذا البرنامج. 


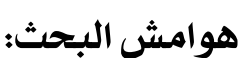

محمد بكر: مختار الصحاح، دار الفكر، دار الفكر، بيروت، 1992، ص 630. ابن منظور أبو الفضل جمال الدين: لسان العرب، ط4، دار احياء التراث العربي،

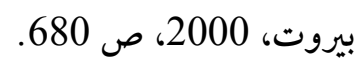

الكبيسي عامر خضير: ادارة المعرفة و تطوير المنظمات، المكتب الجامعي الحديث،

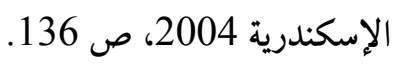

عبد الوهاب على محمد: إدارة الكتاب المفتوح، مقالة في مؤتمر ادارة القرن الواحد و

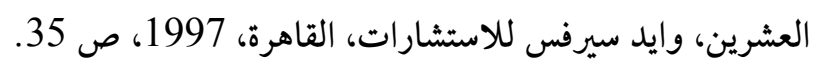

راوية حسين: إدارة الأعمال بتقنية التمكين، ط 3، دار ابن حزم، بيروت، 2011،

$$
\text { ص } 90 .
$$

خالد الميتي: إدارة الموارد البشرية، ط 4، دار وائل للنشر و التوزيع، عمان، 2007،

$$
\text { ص ص 79-84. - (19. }
$$

حجازي محمد حافظ: المنظمات العامة، مؤسسة طيبة للنشر و التوزيع، القاهرة،

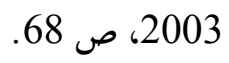

عمر عقيلي: إدارة الموارد البشرية المعاصرة بين الواقع و التطبيق، ط2، دار وائل

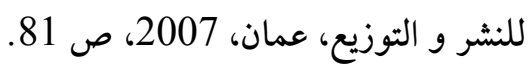

المفرجي عادل حرحوش و آخرون: رأس المال الفكري-طرق قياسه و أساليب

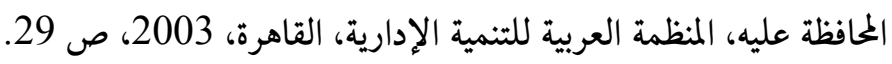

عطية أفندي حسين: تمكين العاملين-مدخل للتحسين و التطوير المستمر، المؤسسة

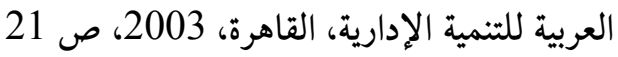

مصطفى أحمد السيد: المدير و مهاراته السلوكية في إدارة الأعمال، المكتب الجامعي،

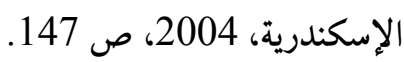




$$
\text { عطية أفندي: مرجع سبق ذكره، ص } 17 \text {. } 11 \text { ما }
$$

علي عبد الوهاب: إدارة الموارد البشرية، جامعة عين شمس، كلية التجارة، 2002،

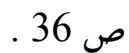

معايعة عادل سالم، اندراوس رامي جمال: الإدارة بالثقة و التمكين-مدخل لتطوير

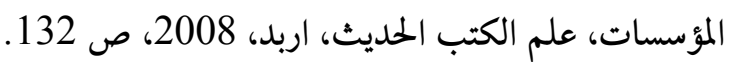

علي محمد ، سالي: العلاقة بين أبعاد التمكين ودرجات الرضا الوظيفي - دراسة

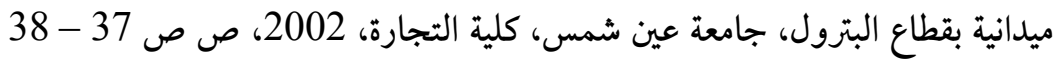

$$
\text { المرجع نفسه: ص صبsi }
$$

(17) William Umiker: Empowerment The Lastet Strategy, Health Care Supervision, 1992, Vol.11, No.12, p. 233.

هاني الطويل: سلوك الأفراد و الجماعات، ط2، دار وائل للنشر و التوزيع، عمان،

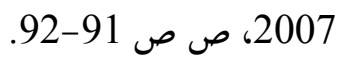

